REVISTA ANDALUZA DE ANTROPOLOGÍA

NÚMERO 15: ACTIVIDADES TURÍSTICAS, CIUDAD Y PATRIMONIO CULTURAL: MIRADAS CRÍTICAS. TOURIST ACTIVITIES, CITY AND CULTURAL HERITAGE: CRITICAL GLANCES

SEPTIEMBRE DE 2018

ISSN 2174-6796

[pp. 198-210]

http://dx.doi.org/10.12795/RAA.2018.15.09

\title{
MOLINIÉ, ANTOINETTE (2016). La Passion selon Séville. París: Bibliothèque de l'Anthropologie. CNRS Éditions, 370 pp.
}

\section{Juan Agudo Torrico \\ Universidad de Sevilla}

Antoinette Molinié es antropóloga, con una larga experiencia en estudios sobre prácticas rituales en los Andes, así como en Andalucía; según se deduce de sus propias palabras en el capítulo introductorio de esta obra, y de las autocitas que encontramos a lo largo de la misma y en las referencias bibliográficas.

Es pues un trabajo que parte de una experiencia contrastada, por lo que pretende ir más allá de una etnografía más que nos dé noticias del interés de unos rituales "sevillanos" sobradamente documentados. Su obra tiene pues la intención de analizar el significado implícito de los mismos, más allá de sus expresiones formales.

Según se desprende del título de la monografía, la ciudad/comunidad de Sevilla es tomada a la vez como unidad de observación y de análisis, a partir de lo que es su sistema ritual. Para ello articula su investigación en cinco capítulos, además de uno primero metodológico en el que expone el marco teórico de referencia, y unas conclusiones recopilatorias: Semana Santa, corrida de toros del Domingo de Resurrección, feria, romería de la Virgen del Rocío y Corpus Christi.

Los rituales y festejos (habría que plantearse el componente ritual de la corrida de toros y de la feria), son analizados siguiendo su secuencia temporal a lo largo del ciclo anual, como acontecimientos festivos ceremoniales que se complementan entre sí, y no según 
un orden de importancia. Si bien esta pretensión se desdice a lo largo del texto, en el que reseña la relevancia incuestionable que tiene la Semana Santa como núcleo simbólico de la sociedad sevillana y, en segundo lugar, la corrida de toros del Domingo de Resurrección. Ambos festejos estarán luego presentes en el análisis de los que le siguen, con recurrentes comparaciones para poner de manifiesto en sus contrastes y continuidades unos valores dominantes transversales a todo el sistema ritual sevillano.

El procedimiento seguido en cada capítulo parte de una contextualización histórica, para seguidamente realizar una descripción etnográfica del presente y culminar con la consiguiente interpretación de sus significados y valores simbólicos. Para ello recurre a una prolífica reseña de la abundante bibliografía existente, incluidas abundantes referencias a la documentación de las propias cofradías, complementadas con numerosas notas pie de página que tratan de explicar a los foráneos las peculiaridades de estos rituales y el léxico localista que impregnan todo el proceso.

Dicho lo cual, la obra, pese a su considerable número de páginas (370) y densidad del texto, no deja de ser ambiciosa, si tenemos en cuenta la complejidad de cada uno de los temas tratados. Y sobre todo, según reseña reiteradamente la autora, que no se trata de un libro de viajes para iniciados o de una etnografía acerca de las singularidades de los rituales sevillanos, sino de un análisis en el que estos rituales, ahora sí, son tomados como unidades de observación para adentrarnos en los valores, comportamientos colectivos y actitudes psicológicas de los sevillanos (en masculino), que subyacen en todos y cada uno de ellos. Sin que importe que sean expresiones festivo-rituales tan dispares como la Semana Santa y las corridas de toros, o una romería y los festejos del Corpus.

Sin embargo, desde mi punto de vista, sobre todo si tenemos en cuenta los continuos comentarios, aislados pero contundentes, que va insertando a lo largo del texto sobre colectivos como los gitanos, sobre el papel asignado (no el que desempeñan) las mujeres sevillanas, la omnipresente recurrencia a los valores de masculinidad, vergüenza, honor, lucimiento, etc., que los impregna, el trabajo se mueve a caballo entre una cuestionable mirada antropológica y viejas imágenes de antiguos libros de viajes, cargados de tópicos sobre los comportamientos y valores sevillano-andaluces que parece ser constituyen nuestra idiosincrasia colectiva.

Los objetivos pretendidos se ponen de manifiesto en las páginas iniciales. Se trata de estudiar el "... cycle festif sévillan: une semaine sainte ambigüe, une ferie élégante et un pèlerinage convulsif." (p. 17), desde la perspectiva de una antropología del ritual y un enfoque analítico freudiano. A partir de la propia particularidad del modo como son reinterpretados los dogmas del catolicismo en Andalucía: “Á plusieurs reprises, au cours de mes observations, l'idée m’est venue que les Indiens des Andes étaient plus respectueux du do me catholique que les Andalous qui peuvent apparaître, à beaucoup d'égards, comme des idolâtres." (p. 29). Aunque el enfoque teórico-metodológico seguido 
en su análisis tal vez donde mejor queda de manifiesto es en las páginas finales del texto: "Nous avons reconnu, dans les relations que construit le cycle rituel dans ses marges, les différents conflits du complexe d'Edipe et leur résolution. Nous avons procédé, à titre heuristique, par analogie, non pas taerme à terme en identificant simplement tel personnage de l'Oedipe dans tel personnage du rite, mais en recherchant la symbolique oedipienne dans les relations: celles qui se nouent tout an long du cycle, entre Notre Pére Jésus, la Douloureuse et les confréries, soit les trois sommetse du triangle oedipien; celles qui s'exhibent dans l'aréne entre le toro bravo, le matador et son public; celles qui leint la Virgen del Rocio at ses kidnappeurs et a ses confréries; celles que produit la consommation de l'eucharistie par les corps constitués défilant devant le Saint-Sacrement. Nous avons ainsi constaté la cohérence de l'autre récit du cycle rituel, celui du conflit oedipien et de sa résolution. On notera dans cette perspective, comment les deux approches, structurale et psychanalytique, loin de s'exclure, se complètent". En definitiva, "nous avons découvert une maniére collective d'accomplir la parole en tant quacte, avec un investissement affective saturé de sexualité" (pp. 308-310)

Todo ello entremezclado, a su vez, con "quelques réflexions sur la nature du rite, en particulier sa relation avec le mythe". Un recurso metodológico, al parecer complementario, al que recurrirá para poner de manifiesto cómo la puesta en escena de estas representaciones de los mitos religiosos responden (también) a una finalidad de control social, de imposición de unos dogmas, que contrasta con el modo como se reinterpretan y viven estos mismos dogmas en los márgenes del ritual. Pero no deja de sorprender que entre la amplia bibliografía manejada no aparezca ninguna cita a la obra de autores que han reseñado precisamente esta función sociopolítica del ritual, como puedan ser V. Turner, E. Leach, P. Scarduelli, ... o incluso pioneros como E. Durkheim.

En realidad todo el trabajo parte de un uso de la interpretación simbólica de las prácticas sociales como prácticas culturales con valor en sí mismas, no como reflejo de una realidad social compleja y polisémica. Desde esta perspectiva se recurre a una interpretación antropológica simbolista donde la realidad social sólo es tenida en cuenta como factor secundario, para justificar los hechos (valores) que se priorizan.

No se trata de cuestionar el hecho de que los comportamientos y/o interpretaciones simbólicas son inherentes a buena parte de nuestras prácticas socioculturales, y no solo las vinculadas al campo del ritual. Son precisamente estas interpretaciones simbólicas los mecanismos por los que, de una forma u otra, legitimamos, reforzamos o cuestionamos los valores sociales con los que se vinculan. Pero cuando se parte de una lectura más que simbólica simbolista, forzando a una visión univoca de las realidades sociales (más bien de los comportamientos sociales) analizadas acorde con los presupuestos simbólicos previos, la cuestión cambia. 
En este caso se predetermina un eje freudiano (explícitamente recogido en el epígrafe introductorio, "Un éclairage freudien") por el que se pretende demostrar que todos los comportamientos ritualizados analizados se rigen por una seducción sexualizada latente en unos casos (reprimida y contradictoria), y explicitada en otros, hasta adquirir una condición de práctica sacralidad en la representación de la corrida de toros del Domingo de Resurrección. Afirmación que queda meridianamente explicitada en el curioso resumen con el concluye el capítulo dedicado a la feria de la pág. 181 ("Conclusion: à lauge de la société")

Con una variable muy a tener en cuenta, y a la que nos vamos a ir refiriendo a lo largo del texto, y es que este juego de comportamientos-valores y de seducción reprimidaexplicitada no se justifica al modo clásico para evitar la supuesta conflictividad que conllevaría una sexualidad desbordada, sino como reafirmación indiscutible del valor dominante que, según la autora, se da a la masculinidad de los sevillanos-andaluces. De ahí que lo que se pone en juego son estos valores varoniles amenazados por las mujeres andaluzas (honor, vergüenza, familia); unas mujeres que únicamente adquieren valor según sea su vinculación (¿propiedad?) a estos hombres: hijas, hermanas, esposas. Pero unas transgresiones de honores y vergüenzas que se convierten en blasones laudatorios cuando son los hombres quienes las realizan; véase al efecto la "curiosa" referencia que se hace al papel que juegan los hombres y mujeres gitanas en este contexto, a la que luego nos referiremos.

Como contrapunto, que no vendría sino a reafirmar estos valores dominantes, el culto a la Virgen María (mariolatría) ocupará un papel dominante en este imaginario (ritualizado) andaluz. Es a la vez una diosa-madre con todo lo que ello supone en relación con el papel que desempeña la figura materna en la cultura andaluza (mediterránea); y una diosajoven que no puede sino dar pie a una sensualidad/sexualidad que ha de ser reprimida entre quienes la han convertido en un símbolo de madre-mujer a la vez.

Por el contrario, en las descripciones y análisis de los festejos y rituales descritos, se nos dice muy poco, o sólo como obligada referencia a sus procesos históricos y por citas entresacadas de los autores consultados, de la compleja y jerarquizada estructura social de la ciudad de Sevilla, reflejo de la andaluza. Ciertamente los rituales analizados reflejan meridianamente esta complejidad socioeconómica y sociopolítica y es, como indica la autora, en su complementariedad cuando mejor se percibe, al ser interpretados como parte de un sistema ritual, y no de forma aislada (que también). Y como todo ritual, tienen la finalidad y función de poner en evidencia este juego de contradicciones, no en pocas ocasiones afirmándolas y negándolas (communitas simbólica) al mismo tiempo.

Es inevitable que estén presentes las variables sociopolíticas en el análisis de los rituales sevillanos, como expresión cambiante de su estructura social. Y sin embargo las referencias que la autora hace a esta cuestión son más bien escasas, de pasada. 
Buen ejemplo de ello es la descripción que realiza, dentro de lo que considera los márgenes del ritual, de las "cofradías pirata", y el modo un tanto heterodoxo (acorde con la imagen dominante, ortodoxa, del modo como han de comportarse los nazarenos y el trato que hay que dar a las imágenes desde que salen hasta que entran) como se comportan las cofradías de los barrios periféricos una vez que han salido de los circuitos oficiales. Llega a hablar del "aspecto carnavalesco", reseñando la participación como protagonistas de los niños en estos desfiles procesionales, lo cual (p. 45) podría llegar a suponer un riesgo para el propio ritual: "Les frontières entre les catégories que constituent le rituel étant de plus en plus perméable (entre enfant et adulte, entre homme et femme, entre rite de carnaval et rite de pénitence, entre quartiers) le rituel s'en trouve peu à peu déconstruit et perd son sens premier", algo que afecta sobre todo a las muchas cofradías de barrio "Cependant le seuil à partir duquel le rite se folklorise est loin dêtre franchi".

También entra en el debate, ya circunscritos a los patrones de normalidad propios de la Semana Santa, sobre si la Semana Santa ha de ser interpretada desde la ortodoxia eclesiástica, como manifestación de fe sometida a los dogmas incuestionables de la Iglesia, o como "hecho cultural" de interpretación más abierta. Interesante el análisis que realiza del papel que desempeña el transcurrir de las cofradías por el recinto de la catedral, y alguna otra apreciación sobre el permanente conflicto entre los deseos de reafirmación de las diferentes cofradías acorde con los universos sociales que representan (barrios, sectores sociales, condiciones de clase), y el poder institucionalizado, homogeneizador, representado por la Iglesia y el arzobispado.

Por el contrario, no dejar de ser llamativo, dentro de esta obsesión simbolista, el modo como analiza la procesión del Corpus. Después de la interpretación histórica del origen del ritual y de pasar muy por encima sobre su significado sociopolítico como la procesión cívica que es, y donde se pone de manifiesto una imagen idealizada del conjunto de la sociedad sevillana convenientemente jerarquizada, lo que a la autora le interesa es su "significado simbólico" (lo anterior es mera expresión de la realidad social sin otras valoraciones), recurriendo ahora a una centralidad de los niños (?) en el ritual, y a lo que este ritual representa como testimonio de una "castración simbólica", y del recuerdo de los judíos como infanticidas, en un discurso que, a decir verdad, he sido incapaz de seguir y, por lo tanto, de entender. Sorprendentemente en esta ocasión nada se nos dice de la ausencia de un "pueblo" llano, convertido en mera comparsa como espectador; frente al protagonismo que este mismo pueblo ha tenido y tiene en los demás festejos, contribuyendo a convertirlos en unos rituales populares llenos de vitalidad y contrastes. En todo caso, el papel dominante que juega la Semana Santa en el imaginario sevillano, hace que sea este el capítulo más denso y mejor documentado. Como expresión simbólica conforma un código difícil de desentrañar para un "no sevillano": cada imagen representa de un modo u otro a determinados grupos sociales ("dimension classificatoire"), de 
barrio, clases sociales, étnicas, manifiesta a través de los objetos-símbolos que porta, de su indumentaria, del modo como es tratada. Las procesiones no siguen una secuencia lógica a la hora de desfilar siguiendo el proceso de Pasión de Cristo. No lo pretenden, porque en realidad cada paso, las imágenes que portan y lo que representan, tiene valor en sí mismos, no por su contextualización en el ritual: "Chaque paso exhibe une divinité dans sa spécificité irréductible." (p. 47). Si, bien, en contraposición, cada talla sí representa una secuencia de la historia de la ciudad, remitiendo a periodos históricos, estilos artísticos, autorías, que nos hablan de un largo y complejo proceso histórico, y que ha dado lugar a un rico y variado patrimonio cultural que se refleja en estas imágenes, en los enseres con los que se vinculan, y las tradiciones culturales que envuelven sus recorridos, leyendas de origen y particularidades en el modo de ser procesionadas: "le savoir des confréries constitue une véritable mémoire de la ville, comme si l'histoire de celle-ci était en quelque sorte démembrée en autant de Christ et de Douloureuses, et recomposée à chaque semaine sante dans la procession commune”. (p. 48). Un vínculo que también se transmite al ámbito de la familia, en las sagas de familiares que han estado vinculados a cada cofradía, pero también en los muchos de los bienes de estas cofradías donados, e identificados, con determinadas personas-familias, con lo que adquieren un valor "totémico".

Aun así, dista mucho de ser analizado como reflejo de la sociedad sevillana, de su estructuración espacial (barriadas) que también lo es socioeconómica, de los juegos de poder que se desarrollan en sus organizaciones, dentro de unas cofradías que son reflejo de la sociedad cambiante que les da vida; y en definitiva de una Semana Santa como expresión de una tradición que para que siga viva ha de estar cambiando permanentemente. De hecho, la imagen que se nos da es todo lo contrario: es la de una Semana Santa inamovible al paso del tiempo, si no en sus expresiones formales sí en sus valores. Curiosamente los cambios sí son bien aceptados cuando reafirmarían estos valores, como ocurre con los costaleros de hermandad, que vendrían a añadir, en apreciación de la autora, un nuevo marcador para reafirmar la masculinidad de los varones sevillanos. Pero cuestionable, siguiendo el mismo patrón de análisis, cuando afectan a las mujeres. Según la autora, las cofradías siguen siendo "maison des hommes" donde están mal vistas las mujeres: "Nombreux sont les Sévillans qui se plaignent des nazarenas. Les tailleurs n’apprécient guère cette clientèle: alors qu’on peut confectionner un habit masculin en quelques heures, les femmes ont des exigences, selon eux, ridicules. Par ailleurs les hommes supportent mal dêtre dirigés par une nazarena à qui on confie une responsabilité dans une procession". (p. 44) Aunque tal vez hayan contribuido a reforzar, siguiendo este mismo patrón de interpretación, la sexualidad veladas que subyace a todo ritual sevillano y que, no podía ser de otro modo, se materializa en los propios nazarenos: "Et il ne prend guère la peine de dissimuler le plaiser qu'il prend à jouer avec le secret de sa cagoule. On observe dans les files de processions des échanges de séduction dissimulés 
derrière de faux anonymat de l’uniforme de la confrérie. ” (p. 93)

El resultado, confirmando las ambigüedades inherentes a todos los rituales analizados, vendría a ser las falsas contradicciones con las que se mira este ritual desde "fuera", como manifestación de un festejo hipócrita. La concepción ortodoxa de la Semana Santa como tiempo de penitencia y expresión de dolor, vendría a contrastar con la alegría con la que se vive en la calle el festejo; ningún momento lo expresaría mejor que la madrugá del jueves al viernes, cuando ambos imaginarios se entremezclan: exaltación del tiempo de pasión y ocupación desbordada, bulliciosa y alegre, de las calles de Sevilla.

Si bien, todo este mundo contradictorio y complejo tendría una lectura aunque profunda sencilla: ... "nous avons découvert, dans notre ethnographie des marges du rite, les composantes de l'atome de parenté, les protagonistes du conflit œedipien: Notre Pere Jésus dont les processions célèbrent la mort, la jeune Douloureuse que la rue s'approprie, et le Sévillan ordonnateur du rituel qui se trouve ainsi dans une position profondément ambivalente. S'il assiste au théâtre ofliciel de la Passion en tant que spectateur, il est, dans le théâtre de l'inconscient, un acteur central, et il y intervient même comme partie prenante." (p. 109)

En el análisis de los otros rituales esta desvinculación con los entramados sociopolíticos en los que se insertan, y que contribuyen a reafirmar o negar, se acentúa, para desbordarse sus significados freudianos. La corrida del Domingo de Resurrección es considerada el colofón de la Semana Santa. El tiempo de la sexualidad freudiana reprimida da paso a un erotismo explícito que se propagará por los festejos y romerías por venir. Dentro de la correspondiente revisión bibliográfica para contextualizar el origen histórico de La Maestranza y de los toros en España-Andalucía, se referencia de pasada el papel que ha jugado la Maestranza-Maestrantes en el imaginario de la oligarquía señorial sevillana. Pero poco se nos dice, dando por sentado que los toros-bravura-virilidad son valores inherentes al mito de origen de la fiesta, del por qué la tardía presencia de esta plaza entre los espacios públicos sevillanos (s. XVIII-XIX), al compás que van surgiendo en otros lugares de la mano de una nueva burguesía agraria que busca espacios donde mostrarse y ser vista. Al tiempo que los toreros sustituyen a los caballeros, y entronca con un imaginario de cultura popular que ve en el valor forzado de los mismos la única manera, con suerte, de salir de la pobreza. ¿Se mantiene este imaginario en el presente?.

La interpretación que se nos hace de la corrida sigue al pie de la letra la teoría del antropólogo ingles J. Pitt-Rivers, de acto ritual, de sacralidad marcada por la consiguiente exaltación de la virilidad del torero y el sacrificio mítico del toro. Las constantes citas (apoyadas en una selección de imágenes no menos explícita) a este autor vendrían a confirmar la validez de sus afirmaciones. Y así queda recogida en la secuencia de unos epígrafes con títulos tan elocuentes como "La corrida de Resurrección: la clarté solaire après les ténèbres", "La corrida et la messe", "Le torero en ministre du culte" o "La 
mort du taureau: un sacrifice". Argumentaciones que vendrían a ser confirmadas por semejantes prácticas rituales desarrolladas en otros lugares de Andalucía: "En effet, après les processions de la semaine sainte, les courses au toro del aleluya puis la procession du jeune Ressuscité, semblent célébrer un retour de la sexualité après le parricide. Cette hypothèse est confirmée à Arcos de la Frontera par les démonstrations de virilité auxquelles se livrent les garçons du village le dimanche de Pâques, lors de la course au toro del aleluya. Celle-ci prend la dimension d'un rite de passage à lâge d'homme. En effet, il faut avoir au moins seize ans pour obtenir l'autorisation de la mairie pour courir le taureau, et il est clair que les adolescents nattendent pas cet âge-là pour prouver leur virilité." (p. 135)

La feria reafirma el contrapunto a la imagen de tristeza y autorepresión que fuera la Semana Santa.

En la pormenorizada descripción etnográfica que nos hace de la feria no deja de reseñar algunos de los valores que van a significarla, más allá de sus expresiones formales, como es el encubrimiento simbólico de los intercambios monetarios como forma de pago en las casetas, para dar rienda a un simbólico modelo de sociabilidad basado en el agasajo y una reciprocidad altruista y generalizada de visitas entre casetas; o el papel que juegan estas casetas como contrapunto abierto del concepto cerrado de los ámbitos domésticos sevillanos/andaluces. Si bien más tarde (p. 178) considera a estas casetas como una trasposición de estos ámbitos domésticos, como casetas familiares ("foyer éphémerè en miniature") en las que se reproducen las mismas limitaciones, tanto de intimidad como de condición social de a quienes se invita y con los que se convive. Ambos rasgos volverán a hacerse presente en el desarrollo de la romería del Rocío, aunque en esta ocasión las carretas actuarían como una reafirmación de la imagen de la familia en el contexto del ritual.

La feria vendría a ser el festejo donde mejor se visualiza la compleja sociedad sevillana, tanto en la expresión formal de una ciudad efímera que permite percibir en sus calles y casetas los diversos colectivos que la componen; como en los valores sociales que recrean, no siempre precisamente de igualdad: "On comprend qu’on joue ici à une société qui disparaît peu à peu dans l'indifférenciation sociale progressive. Mais la distinction Ancien Régime est toujours présente dans les modes de sociabilité, dans les choix esthétiques, dans un idéaltype aristocratique de l'homme d'honneur." (p. 173)

Acorde con el hilo conductor de la obra, la feria no vendría a ser sino la ocasión donde se explicitan los vínculos de sexualidad/sensualidad, y valores de feminidad/masculinidad que articulan la cultura y sociedad sevillana/andaluza. Unos valores y comportamientos que se ocultan/reprimen en los demás rituales de carácter religioso.

La romería del Rocío, bien conocida de la autora según se desprende de su bibliografía, 
ocupa igualmente un papel destacado en este trabajo. Con ello se quebraría en teoría el punto de partida por el que Sevilla-ciudad es tomada como unidad de observación y análisis; salvo que, acorde con un imaginario ampliamente extendido, sea el Rocío "la" romería de Sevilla, cubriendo así un peculiar vacío de esta ciudad que carece precisamente de unos de los tres pilares (junto a la Semana Santa y la feria) que caracterizan los sistemas rituales de la inmensa mayoría de las agrociudades andaluzas. Sin que lo que acabamos de decir invalide el indudable protagonismo que esta romería/devoción tiene en Sevilla ciudad, con la peculiaridad de ser la población representada con un mayor número de cofradías filiales.

Sin embargo en la pormenorizada etnografía que realiza de la romería, la presencia y protagonismo de la ciudad de Sevilla se diluye poco después de comenzar el capítulo, aunque no por ello deje de recurrir a la consabida comparación con la Semana Santa como patrón de referencia, poniendo de manifiesto (no podría ser de otro modo) la radical diferencia respecto a este otro modelo de ritual. Dicho lo cual, y una vez reconocido el protagonismo de la población del Almonte (sin olvidar el conflicto ritual y simbólico con la otra población de Villamanrique) y de los jóvenes almonteños que protagonizan el control de la imagen, de nuevo las connotaciones psicoanalítiticas de los conflictos del uso simbólico de la imagen de la Virgen como trasfondo de tensiones emotivas/sexuales y comportamientos en muchos casos edípicos, cuando no claramente transgresoras, se convierten en lo que, según la autora, es en realidad el patrón dominante en los comportamientos rituales "andaluces"; solo que ahora representados por los jóvenes almonteños.

Nuevamente se echa a faltar la interpretación de esta romería también en claves socioeconómicas; en lo que representa y manifiesta de afirmación/negación no menos simbólica de un determinado orden social. Las propias hermandades sevillanas reflejan la diversidad de su estructura social. El uso emblemático de caballos, carretas, casas de hermandad y particulares, reflejan a la vez la desigualdad y jerarquización social de la sociedad andaluza, y el cuestionamiento simbólico de la misma; recreando un espíritu de communitas, de igualitarismo simbólico, manifiesto en muchos aspectos de la romería, incluido el propio transcurrir por los caminos que llevan a la ermita. Como también ha sido analizado, no precisamente en clave edípica, el factor de rebeldía que supone el control de los jóvenes almonteños sobre la imagen, transgrediendo (temporalmente) en muchos aspectos el orden ideal que debiera regir en modo de tratar y comportarse con estas imágenes sagradas, según establecen los cánones impuestos por los poderes eclesiásticos y civiles.

Junto a la Semana Santa y la feria, la interpretación de la romería del Rocío constituye el tercer pilar prioritario de su análisis. Viene a ser una clara afirmación de sus hipótesis de partida. Los títulos de los epígrafes no pueden ser, de nuevo, más elocuentes: "Se mettre 
sous la Vierge: le rapt de la déesse", "Una hyperbole de la virginité" ... De ellos, el que lleva por título (p. 205) "L'initiation des garçons: le corps de la Vierge", constituye de por sí un capítulo denso, en que se nos viene a decir, nuevamente, que el trato que recibe la Virgen ha de ser interpretado como la ambigua relación de sexualidad mantenida entre hombres y mujeres "andaluzas", siempre bajo la espada de Damocles de la exaltación y defensa del "honor" de los hombres que han de velar por "sus" mujeres.

Unas páginas más adelante (p. 229) desarrolla un epígrafe que en cierta manera sintetiza buena parte de sus teorías. Lleva por título "Honor et vergüenza: les valeurs transmises par le ritual". Dos términos, honor y vergüenza, omnipresentes a lo largo del libro, acaparan ahora un epígrafe propio. Las mujeres andaluzas vuelven a ser tomadas como referente (exaltación/represión) de una masculinidad que, según parece, es el dominante absoluto de "la cultura" andaluza.

Es un epígrafe breve, de apenas cinco páginas, pero resulta difícil de recrear en tan pocas palabras todas las imágenes más simplistas y descontextualizadas según interese a la autora del papel asignado a la mujer en el imaginario cultural andaluz: véase al efecto la curiosa interpretación del por qué a la mujer se le asocia con la imagen de maldad de las serpientes, pero también de la peculiar utilización en el léxico andaluz de diversas palabras relacionadas con los órganos sexuales masculinos; a lo que podemos unir la interpretación que en páginas anteriores realiza la autora de los términos/valores "santito", "golfo" "tito", aplicados al comportamiento de los jóvenes almonteños y su relación con la imagen de la Virgen. Todo ello en clave de honores y vergüenzas, de controles de sexualidades desbordantes que hay que reprimir, de honores de familias como patrimonios a defender, etc., como valores, si alguna vez los hubo (¿todos los sectores sociales, en todos los tiempos?) que, según la autora, siguen rigiendo todos nuestros comportamientos rituales, nuestras relaciones sociales: "La nécessité absolue pour un homme de préserver son honneur vient d'une croyance: il s'agit, à l'instar du sperme, d'un bien non renouvelable. Une fois entaché par une femme, il nest plus réparable. On dit que l'honneur est comme un verre brisé". (p. 232)

El machismo (encubierto de masculinidad) parece ser una práctica inherente a la cultura andaluza, expresada abiertamente en los rituales descritos, y plasmado, según la autora, en la realidad social. En la página 230, siempre hablando en tiempo presente y como valores inherentes, se dice sin ambages: "les andalous contrôlen jalousement le champ social des leurs femmes, épouses, filles ou soeurs. ... Les relations entre le père d'une jeune fille et l'amoureux de celle-ci, trés tendues pendant la durée de la cour, deviennent excellentes dès que les fiançailles son officielles. La rivalité se transforme alors en solidarité virile por surveiller la future épouse". Frase esta última sin desperdicio, si hablamos de un presente, de cómo se viven las relaciones sociales de género e incluso intrafamiliares en la mayor parte de las familias andaluzas; pero que sí serviría para tratar de justificar, por aquello 
de la "solidaridad viril" (?) la continuidad de unos comportamientos machistas que la inmensa mayoría de la sociedad andaluza rechaza.

De manera algo más tangencial no dejan de aparecer referencias que reafirman los grandes tópicos sobre esta romería, como la sexualidad desenfrenada que caracteriza la convivencia durante el camino a la ermita, o el protagonismo que tiene el colectivo homosexual en la misma: "Lintense recueillement des marcheurs autour du simpecado et les chants poignants qui lui sont adressés au clair de lune contrastent avec l'ambiance orgiaque de certaines nuits dans la pinède qui voient tomber tous les tabous. Quelques chars à bœufs d'homosexuels évoquent plus une gay pride qu'un pèlerinage à un lieu saint: des hommes aux jupes et aux châles de flamencas, avec des fleurs sur la tête, forcent le trait par leur maquillage, leurs bijoux en plastique, leurs jeux d'éventail et leurs danses lascives: de vraies scènes d'Almodovar animent ainsi le sanctuaire de la Vierge. Les familles se complaisent de ces spectacles inimaginables dans la vie réelle. Souvent le voyage pieux prend des allures de carnaval et les nuits des jeunes pèlerins sont ponctuées d'orgies." (p. 190)

Dicho lo cual, como no podía ser menos, la romería del Rocío ha de representar a toda Andalucía. No existe, o son referidas de soslayo, referencias a otras relevantes manifestaciones igualmente andaluzas pero que se contraponen ( $\mathrm{y}$ en no pocas veces cuestionan el modelo o al menos el reconocimiento institucional que se da a las manifestaciones rituales de Sevilla-Baja Andalucía) como son la romería de la Virgen de la Cabeza, no menos importante que la del Rocío, o las peculiaridades de otras semanas santas como las de la campiña cordobesa o malagueñas, etc. Aunque la autora no dude en recurrir a comparaciones con otros lugares de Andalucía (Alcalá de los Gazules, Priego de Córdoba, etc.) si contribuyen a reforzar sus afirmaciones.

En consecuencia, la Virgen del Rocío es ya la patrona de Andalucía "Revendiquée par les dirigeants de la región autonome, la Virgen del Rocío est aussi la patronne de L'Andalousie et prend un valeur d'autochtonie toute particulière. ... La Virgen peut même fonder l'autochtonie andalouse d'une généalogie masculine sans perte de virginité" (p. 233)

Entre todo lo dicho existen al menos tres aspectos que desearía reseñar a modo de conclusión. Los tres tienen como punto en común recrear un preocupante imaginario sobre la cultura andaluza del presente.

El primero, reiteradamente aludido en las páginas precedentes, es el papel asignado a la mujer andaluza en todo este juego simbólico. En realidad se podría decir que no están presentes, salvo espejo invertido, como reflejo de lo masculino.

Si existe una palabra repetida hasta la saciedad en el texto, es el término "honor", siempre en clave masculina y teniendo a la mujer (esposa-hija) como garante del mismo. 
Sorprendentemente, cuando se habla de la validez de estos valores todos los tiempos verbales están en presente: no se trata de valores pittriverianos del pasado. Curiosamente, para afirmar la veracidad de sus argumentaciones, lo que no deja de ser preocupante, se retoman palabras de los viajeros del s. XVIII y XIX. De este modo se referencia a J. Blanco White, Richard Ford, o Antonine de Latour para ratificar la sensualidad de la mujer andaluza, y del riesgo que ello ha conllevado y conlleva en el mantenimiento del honor de los maridos/familias andaluzas. Y como muestra de ello, nada mejor que el sempiterno juego del lenguaje de los "abanicos": "Les relations de couple se forment en ces rayonnantes matinées de feria: dans les sevillanas qui enlacent hommes et femmes sans que jamais ils ne se touchent, au cours des parades ou ils exhibent leur élégance complice sur la croupe ornée d'un cheval, tout au long des conversations fleuries d'œillets et d'œillades, sous les chocs joyeux de verres de manzanilla... L'abanico autorise surtout à se livrer à une séduction plus implicite que celle qui aurait recours au langage articulé, et de préserver ainsi l'honneur de l'homme à qui appartient la belle, sœur, fiancée ou épouse. Il émet des messages équivoques; il permet de rendre plus légère une coquetterie enflammée, de se réfugier quand lardeur de la réponse est trop violente et d'attirer un regard fauve par un ouvrir-fermer affriolant. Ce langage mérite à lui seul une étude." (pág. 177)

La segunda referencia que hace es al modo negativo como son referidos los gitanos andaluces en estos contextos rituales. Bien es verdad que, siguiendo la tradición de invisibilizar su existencia y aportación a la cultura andaluza, se les podría haber ignorado por completo, pese al papel destacado que desempeñaron en las ferias andaluzas en muchos de sus aspectos comerciales y festivos, o en el campo del ritual de las semanas santas donde siguen teniendo una presencia relevante. El problema es que las pocas veces que se les nombra son siempre como referencias negativas, aunque se quiera encubrir de una picaresca tolerante. Referencias que no van a ser tanto a los hombres como a las mujeres gitanas y al papel que también desempeñan en el inevitable juego de sensualidades y amores andaluces: "Dès l'origine, les gitans contribuent largement à donner à la feria «les notes les plus brillantes de couleur et de grâce». Ils sont un statut très particulier et ambigu dans la société andalouse. Ils sont réputés voleurs et sans vergogne: l'inverse dc l'homme d'honneur. Mais ils sont à la fois les chanteurs et les danseurs des fiestas flamencas les plus chaudes. Et une caseta de qualité se doit de faire venir un gitan pour mettre de l'ambiance et permettre aux femmes de s'encanailler, activant par leurs regards d'allumeuses, l'honneur des hommes qui les exhibent. À l'inverse, un certain prestige masculin est attaché à celui qui entretient des amours secrètes avec une Gitane, tant il est vrai que celle-ci est réputée ardente et sensuelle." (p. 177)

Finalmente, en tercer lugar, lo que comenzó siendo el análisis de la sociedad y cultura sevillana termina por hacerse extensible a toda Andalucía, a toda la cultura andaluza, 
como un imaginario homogéneo y unívoco, siguiendo el patrón de la Baja Andalucía. Muestra de ello es el capítulo final, las conclusiones, que lleva por título "Le génie andalou du christianisme".

En definitiva, la mirada antropológica que nos ofrece Antoinette Molinié sobre la sociedad sevillana a través de sus rituales está llena de sugerentes apreciaciones, pero también nos refleja la fuerza (preocupante) con la que determinados tópicos sobre el carácter de esta cultura sevillano-andaluza traspasan los tiempos. 